\title{
Characterisation of model compounds and a synthetic coal by TG/MS/FTIR to represent the pyrolysis behaviour of coal
}

\author{
A. Arenillas, C. Pevida, F. Rubiera, R. García and J.J. Pis \\ Instituto Nacional del Carbón, C.S.I.C., Apartado 73, 33080 Oviedo, SPAIN
}

\section{Abstract}

Coal pyrolysis is the initial, accompanying reaction of a number of coal conversion processes such as hydrogenation, combustion and gasification. However, because of the inherent complexity of coal composition, it is difficult to describe coal pyrolysis clearly. Single model compounds have been used before in order to provide additional insight into the complex processes that occur in the pyrolysis of coal. Yet the picture obtained is a simplified one and certain important aspects such as coal structure, interactions between different surface groups and cross-links are omitted. The approach used in this work involves the preparation of a synthetic coal, SC, with a known structure by curing a mixture of single, well-defined model compounds. By means of chemical characterisation, the SC was shown to contain the macroscopic features of a high volatile coal (proximate and ultimate analyses). FTIR characterisation revealed the presence of functional groups similar to those of coal in the structure of the SC. Temperature-programmed pyrolysis tests were performed in a thermobalance linked to a mass spectrometer and a Fourier transform infrared analyser (TG/MS/FTIR). The thermal behaviour of the synthetic coal (i.e., rate of mass loss and the evolution profiles of gaseous compounds during pyrolysis tests) is very similar to that of the high volatile bituminous coal which was used as a reference material. The great advantage of using SC lies in the fact that its composition and structure can be accurately determined and employed in subsequent applications in basic and mechanistic studies.

Keywords: coal pyrolysis, model compounds, TG/MS/FTIR 


\section{Introduction}

Coal pyrolysis is the basic process of cokemaking, and the initial, accompanying reaction of a number of coal conversion processes such as hydrogenation, combustion and gasification. In addition, pyrolysis, performed under defined conditions, is a useful tool for the elucidation of coal structure and for the assessment of its molecular reactivity. In particular, non-isothermal pyrolysis at a constant heating rate can supply mechanistic and kinetic data about the decomposition of coal [1]. However, the pyrolysis process includes a multitude of single reactions that proceed simultaneously and the experimental results represent the sum of the effects of all these reactions. Moreover, the inherent complexity of coal composition makes it difficult to describe coal pyrolysis clearly, although over the last decade many research works have been devoted to this topic [2-4].

Due to general environmental concerns, more effort needs to be put into research on the formation of a series of pollutants from coal combustion (i.e., NOx release). The pyrolysis step exerts an important influence, not only on the coal combustion process, but also on NOx formation, as this controls the distribution of gases, tar and char [5]. However, due to the heterogeneity and complexity of coal, the reaction mechanisms involved in the formation/reduction of NOx have not been completely defined, especially those involving coal char (i.e., heterogeneous reactions). A better knowledge of coal structure and the reaction mechanisms involving nitrogen compounds during pyrolysis may help to reduce and control NOx emissions from coal utilisation.

Single model compounds have been used before in order to provide additional insight into the complex processes that occur in the pyrolysis of coal [6-12]. However, although 
interesting results have been obtained in this way, the picture is a simplified one and some important aspects of coal structure, such as the interactions between different surface groups and cross-links, are omitted in the case of single compounds. Furthermore, in order to study the evolution of nitrogen during coal pyrolysis or combustion, single model compounds containing nitrogen or special surface treatments such as ammoxidation (i.e., treatment with ammonia) have been widely used [8-12]. To study nitrogen reaction mechanisms, the nitrogen must be distributed throughout the bulk of the coal and not just on the surface. In addition, the nitrogen functionalities in the sample must be known.

In order to avoid these problems, we employed a mixture of model compounds that included nitrogen functionalities commonly present in coal. The main aim of the work was to obtain a synthetic coal which is sufficiently representative of the structure, composition and main functionalities of a common bituminous coal with a view to simulating the reaction mechanisms that take place during coal pyrolysis.

\section{Experimental}

\subsection{Preparation of the synthetic coal}

A series of model compounds, shown in Figure 1, were selected and mixed in order to obtain a synthetic coal with a well known structure and composition. Phenolformaldehyde resin (PFR) was synthesised from phenol, formaldehyde and sodium hydroxide [13], and used as a carbonaceous matrix. The resin was then mixed with three model compounds supplied by Aldrich: 3,4,9,10-perylenetetracarboxilic dianhydride (PTC), poly-4-vinylpyridine (p4VP), the source of pyridinic nitrogen, and polyvinylpyrrolidone (PVP), a pyrrolic nitrogen source. In order to create linkages 
between the individual model compounds comparable to those of a real coal, a curing step for the mixture was performed under Ar flow at $5{ }^{\circ} \mathrm{C} \mathrm{min}^{-1}$ from room temperature up to a previously optimised temperature of $425^{\circ} \mathrm{C}$. The final cured mixture was denoted as synthetic coal, SC. It must be pointed out that it was not the aim of this work to simulate the behaviour of a particular coal, but to obtain a material with a well known composition and structure that would be representative of a real coal for subsequent basic and mechanistic studies. Thus, for the purposes of comparison a Spanish high volatile bituminous coal, CA, was used as a reference material.

\subsection{FTIR analysis of solids}

The samples were prepared for solid FTIR analysis following the standard procedure for this type of materials. A coal: $\mathrm{KBr}$ mixture (1:100 ratio) was ground with a mortar and pestle. Pellets were then pressed and dried at $100{ }^{\circ} \mathrm{C}$ overnight. Several pellets were prepared for each sample, one spectrum obtained for each pellet, and an average spectrum produced from the individual ones, in order to minimise any eventual errors arising from grinding and weighing. All absorbance spectra were recorded on a Nicolet Magna IR-560 spectrometer by co-adding 100 interferograms obtained at a resolution of

$4 \mathrm{~cm}^{-1}$. Each spectrum was corrected for scattering, using two baselines (3800-1800 and $1800-400 \mathrm{~cm}^{-1}$ ) and was then normalised to $1 \mathrm{mg}(\mathrm{daf}) \mathrm{cm}^{-2}$.

\subsection{TG coupled to MS/FTIR}

Thermogravimetric (TG) analysis has proven to be a very useful technique for studying the thermal behaviour of a wide variety of solid samples. However, TG analysis by itself does not identify the decomposition products. When TG analysis is coupled with evolved gas analysis, a great deal of additional information can be obtained. In this 
work the pyrolysis tests were performed in a TGA92 thermogravimetric analyser from Setaram (TG) under an argon flow rate of $50 \mathrm{~mL} \mathrm{~min}^{-1}$, employing a heating rate of 15 ${ }^{\circ} \mathrm{C} \min ^{-1}$ up to a final temperature of $850{ }^{\circ} \mathrm{C}$. An MSC200 quadrupole mass spectrometer from Balzers (MS), and a Nexus infrared spectrometer from Nicolet (FTIR), linked to the thermobalance, were used for evolved gas analysis. To avoid secondary reactions, a probe was placed very close to the sample crucible of the thermobalance in the direction of the gas flow. The gas lines between the TG and the MS/FTIR were heated to $200{ }^{\circ} \mathrm{C}$ in order to avoid cold points and thus prevent the condensation of some of the gaseous products.

The MS operated on $100 \mathrm{eV}$ of ionisation energy, using a Channeltron detector (1000 V). The number of $\mathrm{m} / \mathrm{z}$ signals selected gave a temporal resolution of 20 seconds. Although a qualitative analysis was performed in this work, the intensities registered by the MS needed to be repeated in order that the intensity of the peaks of the different samples could be compared (i.e., semi-quantitative analysis). Thus, the signals were normalised to the initial mass of the sample and to the maximum of the total intensity of the experiment [14].

FTIR measurements were carried out using a DTGS detector and a $\mathrm{KBr}$ window, in a specifically developed low-volume gas cell, which was kept at a constant temperature of $225^{\circ} \mathrm{C}$. The interferometer and the gas cell compartments were purged with dry and $\mathrm{CO}_{2}$ free air. The spectra were collected at a resolution of $4 \mathrm{~cm}^{-1}$, and 200 scans were co-added per spectrum. This resulted in a temporal resolution of 106 seconds. 
Each compound detected in the MS and FTIR had its own response factor. By means of the semi-quantitative analysis conducted in this work, it was possible to compare the peak height of the same compound released from different samples. However, in the case of the peaks from different compounds, it was only possible to compare the shape and characteristic temperatures of the peaks. According to the literature on coal pyrolysis, the most important products evolved during the devolatilisation process are $\mathrm{H}_{2}, \mathrm{CO}, \mathrm{CO}_{2}, \mathrm{H}_{2} \mathrm{O}$ and hydrocarbons $[3,15]$. Although it is known that hydrocarbons give several $\mathrm{m} / \mathrm{z}$ signals in the MS corresponding to their fragments, it was found that with the mass spectrometer used in this work, provided with $100 \mathrm{eV}$ of ionisation energy, the main $\mathrm{m} / \mathrm{z}$ signals observed for hydrocarbons were $\mathrm{m} / \mathrm{z} 15$ and 16 , corresponding mainly to the $\mathrm{CH}_{3}{ }^{+}$and $\mathrm{CH}_{4}{ }^{+}$ions, respectively. Although other ionic species were detected during the pyrolysis tests, special attention was paid to the following $\mathrm{m} / \mathrm{z}$ signals (which correspond mainly to the fragments in parenthesis after correcting the possible interferences from other ions): $2\left(\mathrm{H}_{2}^{+}\right), 15\left(\mathrm{CH}_{3}^{+}\right), 18\left(\mathrm{H}_{2} \mathrm{O}^{+}\right), 27$ $\left(\mathrm{HCN}^{+}\right), 28\left(\mathrm{CO}^{+}\right), 30\left(\mathrm{NO}^{+}\right)$and $44\left(\mathrm{CO}_{2}^{+}\right)$. For the sake of simplicity, the mass spectrometer signals will be assigned to the following gaseous species $\left(\mathrm{H}_{2}, \mathrm{CH}_{4}, \mathrm{H}_{2} \mathrm{O}\right.$, $\mathrm{HCN}, \mathrm{CO}, \mathrm{NO}$ and $\mathrm{CO}_{2}$ ), although they really correspond to the ionic species mentioned above.

\section{Results and discussion}

\subsection{Characterisation of the individual model compounds}

The ultimate analysis of the individual model compounds is presented in Table 1. These compounds are free of mineral matter and sulphur, implying the absence of catalytic effects during the pyrolysis tests. The p4VP sample has a high hydrophilic character (48.7\% moisture). 
Figure 2 shows the infrared spectra of the individual model compounds. According to the reference data [16-17] a correspondence between the absorption bands and functional groups can be established. Thus a very broad and intense absorption band at $3700-2800 \mathrm{~cm}^{-1}$, arising from $\mathrm{O}-\mathrm{H}$ bonds, is observed in the spectrum of PFR, due to the high concentration of phenolic groups. The presence of a small absorption in this area in the spectrum of $\mathrm{p} 4 \mathrm{VP}$ is due to the high hydrophilic character of the compound. In the $3050-2850 \mathrm{~cm}^{-1}$ area, clear differences can be observed in the spectra, due to different proportions of aliphatic and aromatic $\mathrm{C}-\mathrm{H}$ bonds in the samples. PTC presents very clear absorption in the $1800-1700 \mathrm{~cm}^{-1}$ area and at $\approx 1030 \mathrm{~cm}^{-1}$, due to anhydride groups. As for the $\mathrm{N}$ functional groups, PVP displays a strong absorption at $\approx 1600 \mathrm{~cm}^{-1}$, typical of the $\mathrm{C}=\mathrm{O}$ stretching of amides. Sample p4VP shows several bands between 1650 and $1200 \mathrm{~cm}^{-1}$, which are characteristic of the ring breathing vibration of pyridinic compounds. Finally, PTC and PFR also display bands of benzenic breathing vibration in the $1600-1500 \mathrm{~cm}^{-1}$ area, and a great complexity in the $1350-1000 \mathrm{~cm}^{-1}$ area, with numerous bands arising from $\mathrm{C}-\mathrm{O}$ stretching and $\mathrm{O}-\mathrm{H}$ deformation vibrations.

The individual model compounds were pyrolysed in the TG/MS/FTIR system. Variation in the rate of mass loss with temperature for each compound is shown in Figure 3. The profiles obtained from the $\mathrm{TG}$ analysis were deconvoluted, using a mixture of Lorentzian and Gaussian functions. Thus, the PFR profile can be divided into 5 different peaks, due to its complex structure, while the other three compounds (PTC, p4VP and PVP) present a single peak profile. The results from the TG analysis were related to the evolution of different gaseous compounds detected by MS and FTIR $\left(\mathrm{H}_{2}, \mathrm{CH}_{4}, \mathrm{H}_{2} \mathrm{O}\right.$, 
$\mathrm{CO}, \mathrm{CO}_{2}, \mathrm{HCN}, \mathrm{NO}$, phenol and monomers e.g. pyrrolidone and 4-vinylpyridine). These are shown in Figure 4 (MS profiles) and Figure 5 (FTIR profiles).

The advantages of using model compounds are that their functional groups are already known, they can be easily related to the TG and the evolution profiles of the gaseous compounds and reaction mechanisms can be proposed. For instance, the PTC single peak (between 500 and $650{ }^{\circ} \mathrm{C}$ ) observed on the DTG curve (see Figure 3 ) is due to the breaking up of anhydride groups (single process) with the formation of $\mathrm{CO}$ and $\mathrm{CO}_{2}$, as can be seen in the MS profiles of Figure 4 and corroborated by FTIR in Figure 5.

The DTG curve for p4VP (Figure 3) again shows a single peak but at lower temperatures $\left(350-500^{\circ} \mathrm{C}\right)$. This indicates that a single process is also occurring during the pyrolysis of this compound. As no nitrogen compounds were detected either by MS or FTIR, it seems clear that the rupture of the six-member ring (cf. Figure 1) has not taken place. $\mathrm{CH}_{4}$ detection, from lateral chains of the polymer, was negligible according to the MS (Figure 4) and was not detected by FTIR due to its lower level of sensitivity. The only gaseous compounds detected, apart from moisture, were $\mathrm{H}_{2}$ by MS (see Figure 4) due to condensation reactions, and the monomer 4-vinylpyridine by FTIR (see Figure 5), indicating that the breaking up of the polymer into monomers seems to be the main process occurring during the pyrolysis of $\mathrm{p} 4 \mathrm{VP}$.

A single peak between 350 and $500{ }^{\circ} \mathrm{C}$ was also observed in the DTG profile of PVP (Figure 3). Breakage of the five-member ring leads to the formation of $\mathrm{CO}$ and $\mathrm{CO}_{2}$ due to the oxygen content of the sample, as can be seen in Figures 4-5. The rupture of the ring leads to the formation of nitrogen compounds (i.e., $\mathrm{HCN}$ and NO) presented in 
Figure 4. The interferences of other fragments in $\mathrm{m} / \mathrm{z}$ signals 27 and 30 have been taken into account and subtracted [18]. The formation of NO in a reducing environment can be justified by the presence of oxygen in the PVP composition, as in coals, where NO has also been detected [18-22]. The fact that the detection of HCN and NO by FTIR is negligible, is surely due to the lower sensitivity of the equipment compared to the MS. This also explains the small detection of $\mathrm{CH}_{4}$ by $\mathrm{MS}$ and the negligible intensity in the FTIR. However, FTIR is sensitive enough to detect the monomer, pyrrolidone, shown in Figure 5.

The DTG curve of PFR can be divided into 5 peaks (see Figure 3). The first and second peaks appear at temperatures lower than $300^{\circ} \mathrm{C}$. They therefore arise mainly from moisture, $\mathrm{CO}$, and $\mathrm{CO}_{2}$, as can be observed in Figures 4-5. The elimination of ether and methylol functions from the PFR [23] or the evolution of unreacted formaldehyde could be the main source of the $\mathrm{CO}$ and $\mathrm{CO}_{2}$ at such low temperatures. However, in the field of coal research the presence of the so-called mobile phase is generally accepted, comprising the compounds evolved at the very first stage of coal pyrolysis $\left(<400{ }^{\circ} \mathrm{C}\right)$. These compounds (i.e., water and volatile organics) are due mainly to evaporation as they are not chemically bonded to the coal structure [24-29]. Bearing in mind that phenol formaldehyde resins are considered as good representatives of coal structure, the term mobile phase could also be applied to in-lab synthesised resin, which may also make a small, parallel contribution to compounds evolved at low temperatures.

The third peak, between 350 and $500{ }^{\circ} \mathrm{C}$, comes mainly from pyrolytic water and $\mathrm{CO}_{2}$, while the fourth peak $\left(400-600{ }^{\circ} \mathrm{C}\right)$ coincides with the evolution of $\mathrm{CH}_{4}, \mathrm{H}{ }_{2} \mathrm{O}, \mathrm{CO}, \mathrm{CO}_{2}$, and phenol (see Figures 4-5). The rupture of aryl methyl ethers and methylene bridges 
from the PFR leads to the formation of methane $[1,30]$ and probably some $\mathrm{CO}$ and $\mathrm{CO}_{2}$

The fifth peak, centred at $650{ }^{\circ} \mathrm{C}$, can be assigned to some $\mathrm{CO}$, phenol and $\mathrm{H}_{2}$ formation at high temperature. The cleavage of high condensed heterocyclic structures occurs at this temperature [30] with the evolution of $\mathrm{CO}$ and probably some phenolic groups. However, other possible pathways for the production of $\mathrm{CO}, \mathrm{H}_{2} \mathrm{O}$ and $\mathrm{H}_{2}$ have also been suggested by other authors [31-33].

\subsection{Characterisation of the synthetic coal}

The first step in the preparation of a synthetic coal involved the mixing of a series of individual model compounds. After testing different model compounds and proportions, the optimum mixture selected for further studies was 50\% PFR, 10\% PTC, 39\% PVP and $1 \% \mathrm{p} 4 \mathrm{VP}$. The proximate and ultimate analyses of this physical mixture are shown in Table 1. The differences between the values given in Table 1 and the theoretical ones, calculated from the percentages of the single compounds, are negligible. It can be observed that the volatile matter and oxygen contents of the physical mixture present quite high values (67.1\% wt and $20.2 \% \mathrm{wt}$, respectively).

The thermal behaviour of the physical mixture under inert atmosphere was conducted in the TG/MS/FTIR system and the DTG profile obtained is shown in Figure 6. This profile can be deconvoluted into four different peaks, which can be assigned to the species followed by MS and FTIR. In addition, the characterisation of the individual model compounds previously described allowed the MS profiles of the physical mixture to be related to the individual model compounds and their functionalities. Thus, the DTG curve presented in Figure 6 can be divided into two main zones: the first one 
between 100 and $300{ }^{\circ} \mathrm{C}$, and the second one in the temperature range of $350-600{ }^{\circ} \mathrm{C}$. DTG deconvolution gave two peaks in the first zone that correspond to the moisture, $\mathrm{CO}$ and $\mathrm{CO}_{2}$, released from the resin, PFR. The second zone of the DTG curve can also be divided into two peaks. The main one (peak 3 in Figure 6) corresponds mainly to $\mathrm{CO}, \mathrm{CO}_{2}$, pyrolytic water and the evolution of monomers, mainly phenol and pyrrolidone due to the high weight of PFR and PVP in the mixture (50\% and $39 \%$, respectively). The small peak at high temperature $\left(>500{ }^{\circ} \mathrm{C}\right)$ could be due to the additional evolution of $\mathrm{CO}$ and $\mathrm{CO}_{2}$ mainly from $\mathrm{PTC}$, and $\mathrm{CH}_{4}$ from PFR.

Although the gaseous compounds evolved during the pyrolysis of the physical mixture are also the most important products obtained during the thermal decomposition of bituminous coals (i.e., $\mathrm{H}_{2}, \mathrm{H}_{2} \mathrm{O}, \mathrm{CH}_{4}, \mathrm{CO}, \mathrm{CO}_{2}$, etc.), the DTG curve of the mixture is not representative of that of common bituminous coals. The peaks at low temperature $\left(<300{ }^{\circ} \mathrm{C}\right)$ do not usually appear in this high proportion, and the main peak is not usually symmetrical, as coal pyrolysis is a complicated process which involves many more reactions than just the breakage of aliphatic chains. Obviously, coal is not a mixture of single compounds but a complex and heterogeneous carbonaceous matrix with different functionalities. Thus, in order to promote linkage formation between the individual model compounds, the physical mixture was cured (i.e., treated at a heating rate of $5{ }^{\circ} \mathrm{C}$ $\min ^{-1}$ up to $425^{\circ} \mathrm{C}$ under Ar flow). During the curing step, release of $\mathrm{CO}, \mathrm{CO}_{2}$ and $\mathrm{CH}_{4}$ took place. The evolution of these compounds is usually related to cross-linking reactions [34].

The sample obtained after the curing step was denoted as synthetic coal, SC. The values of the proximate and ultimate analyses are very close to those of the reference coal CA 
(i.e., high volatile bituminous coal), as can be observed in Table 1. The main differences lie in the absence of ash and sulphur in the SC sample.

Figure 7 shows the FTIR spectra of the physical mixture, the synthetic coal, and coal CA. The differences between the spectra of the physical mixture and the synthetic coal should be noted. The curing step has modified the proportions of aliphatics and aromatics, producing absorption differences in the regions of $3000-2800 \mathrm{~cm}^{-1}$ and 1400 $\mathrm{cm}^{-1}$ (C-H bonds) and also in the $1600 \mathrm{~cm}^{-1}$ band (aromatic $\mathrm{C}-\mathrm{C}$ bonds) [16-17]. There is a clear difference in the $700-900 \mathrm{~cm}^{-1}$ area arising from the aromatic C-H out-of-plane bending vibration [16-17]. The overlapping of bands between 1700 and $1000 \mathrm{~cm}^{-1}$ in the case of SC, clearly indicates the existence of links between the model compounds, as a result of which they form a unique structure.

Although there are some differences between the SC and CA spectra (see Figure 7), it can be observed that, individually, the SC spectrum shows a striking similarity to a typical coal spectrum [35-36]. At least it is much more representative of the structure of the coal than the individual model compounds or their physical mixture. The main differences are due to the higher content of $\mathrm{C}=\mathrm{O}$ groups $\left(1700 \mathrm{~cm}^{-1}\right.$ band $)$ and the absence of mineral matter (1100-1000 $\mathrm{cm}^{-1}$ bands) in SC. The high concentration of $\mathrm{C}=\mathrm{O}$ groups in $\mathrm{SC}$ is in accordance with its high oxygen content in the ultimate analysis. Apart from this, the SC spectrum presents most of the typical absorption bands of coal [35-36] (i.e., aromatics and aliphatics vibrations). Taking into account the complexity and heterogeneity of mineral coals, it can be concluded that the synthetic coal obtained in this work, provides a very good representation of the composition of the bituminous coal taken as a reference material. 
The thermal behaviours of SC and CA were compared in the TG/MS/FTIR system. Figure 8 shows the mass loss profiles during pyrolysis for both samples. It can be seen that the curves almost match, giving practically the same total mass loss and a similar rate of mass loss. From the curves, two characteristic temperatures can be obtained: the temperature of maximum rate of mass loss, Tmax, and the initial thermal decomposition temperature, $\mathrm{Ti}$, which are parameters that depend on the nature of the sample [14]. The $\mathrm{Ti}\left(388^{\circ} \mathrm{C}\right.$ for $\mathrm{SC}$ and $380^{\circ} \mathrm{C}$ for CA), and Tmax values $\left(445^{\circ} \mathrm{C}\right.$ for $\mathrm{SC}$ and $467{ }^{\circ} \mathrm{C}$ for CA) were very similar for both samples. This indicates that they present an analogous thermal response during pyrolysis. The TG results together with the ultimate, proximate, and FTIR analyses are indicative of many similarities in composition and structure between SC and CA. However, a comparison between the evolution of the gaseous compounds released during the pyrolysis of both samples is also needed, as this is related to the functional groups present in the samples.

Figure 9 shows the DTG curve for SC, which can be deconvoluted into four peaks. The main peak is not a symmetrical one, in contrast with the DTG curve of the physical mixture (Figure 5). The curing step has removed the peaks at very low temperature $\left(<300{ }^{\circ} \mathrm{C}\right)$ and has created links between the functionalities, making the pyrolysis process more complex, which is what really occurs during coal pyrolysis. The DTG curve for coal $\mathrm{CA}$ is very similar to the one presented in Figure 9 and it can also be divided into four different peaks centred at the same temperatures.

The first peak in Figure 9 is mainly due to $\mathrm{H}_{2} \mathrm{O}$. Between 400 and $600{ }^{\circ} \mathrm{C}$, bridge breaking starts to fragment the macromolecular network and functional groups begin to 
decompose, producing light species. Degradation of the carbonaceous matrix (peak 2 in Figure 9) starts with the production mainly of $\mathrm{CO}_{2}$ and $\mathrm{H}_{2} \mathrm{O}$ from the more labile oxygenated functional groups (see Figures 10-11 for the MS and FTIR profiles, respectively). The third peak is due to the structural degradation of $\mathrm{SC}$, with some $\mathrm{CO}$ evolution resulting from the break-up of ether-type bonds in PTC, and also from the decomposition of phenols [1], in agreement with the phenolic groups from PFR, as can be seen in Figure 11. The degradation of the carbonaceous structure in this temperature range $\left(500-600{ }^{\circ} \mathrm{C}\right)$ is also corroborated by the evolution of $\mathrm{CH}_{4}$, the rupture of $\mathrm{C}-\mathrm{C}$ bonds and the formation of methyl radicals. $\mathrm{CH}_{4}$ comes mainly from PFR, which is the compound that confers the carbonaceous matrix to the synthetic coal. The evolution of $\mathrm{HCN}$ and NO also occurs in this temperature range (see Figure 10), due to the degradation of the carbonaceous structure, but the amount of these gases is small, and their contribution to the weight loss in the TG is insignificant. The condensation of aromatic structures to char occurs at a higher temperature. This may be associated primarily with the formation of $\mathrm{CO}$ and $\mathrm{H}_{2}$ (peak 4 in Figure 9), PFR being the main contributor to their formation.

Figures 10-11 show the striking similarity (i.e., shape of the peaks and maximum temperatures) between the main gaseous compounds evolved during the pyrolysis of SC and CA. This clearly indicates that the pathways for the formation of the gaseous compounds during the pyrolysis of both SC and CA are similar. The main differences observed come from the evolution of $\mathrm{H}_{2}$, with a better defined peak for $\mathrm{SC}$ than in the case of the bituminous coal $\mathrm{CA}$ due to the condensation of residual phenolic groups from PFR. The $\mathrm{CO}_{2}$ profile for coal CA presents an additional peak that does not appear in the case of SC, due to the decomposition of carbonates at high temperature, which are 
present in CA [14] but absent in SC. It is also significant that SC presents a higher moisture content than $\mathrm{CA}$, but the same temperature peak (at around $600{ }^{\circ} \mathrm{C}$ ) for the pyrolytic water. It should again be emphasised that the main aim of this work was not to simulate a real coal but to obtain a synthetic coal that is acceptably representative of the structure, composition and main functionalities of a common bituminous coal. Taking this into account together with the high heterogeneity and complexity of coal, it can be concluded that the synthetic coal obtained here is representative of a real coal, although some differences in structure and composition were found.

It is worth noting that similarities were found not only for the usual pyrolysis compounds but also for nitrogen compounds (i.e., HCN and NO). This is of special relevance, as the synthetic coal obtained in this work, whose composition and structure are known and which is free of the catalytic influence of mineral matter, may prove very useful for the study of the reaction mechanisms that involve nitrogen during coal pyrolysis and combustion.

\section{References}

[1] K.H. van Heek, W. Hodek, Fuel 73 (1994) 886.

[2] S.C. Saxena, Prog. Energy Combust. Sci. 16 (1990) 55.

[3] P.R. Solomon, M.A. Serio, E.M. Suuberg, Prog. Energy Combust. Sci. 18 (1992) 133.

[4] P.R. Solomon, T.H. Fletcher, R.J. Pugmire, Fuel 72 (1993) 587.

[5] J.M. Jones, P.M. Patterson, M. Pourkashanian, A. Williams, A. Arenillas, F. Rubiera, J.J. Pis, Fuel 78 (1999) 1171.

[6] S. Murata, M. Nakamura, M. Miura, M. Nomura, Energy \& Fuels 9 (1995) 849. 
[7] P. Painter, P. Opaprakasit, M. Sobkowiak, A.W. Scaroni, Prep. ACS, Div. Fuel Chem. 44 (1999) 596.

[8] J.R. Pels, F. Kapteijn, J.A. Moulijn, Q. Zhu, K.M. Thomas, Carbon 33 (1995) 1641.

[9] J.M. Jones, W.A.T. Ellyatt, F.E. Ndaji, K.M. Thomas, Carbon 35 (1997) 217.

[10] H. Schmiers, J. Friebel, P. Streubel, R. Hesse, R. Kopsel, Carbon 37 (1999) 1965.

[11] Z. Wu, Y. Sugimoto, H. Kawashima, Fuel 80 (2001) 251.

[12] K. Stanczyk, Energy \& Fuels 13 (1999) 82.

[13] A.I. Vogel, in Practical Organic Chemistry Including Qualitative Organic Analysis, Longmans, 1961.

[14] A. Arenillas, F. Rubiera, J.J. Pis, J. Anal. Appl. Pyrol. 50 (1999) 31.

[15] W. Wantzl, Fuel Process. Technol. 20 (1988) 317.

[16] L.J. Bellamy, "The infrared spectra of complex molecules" 3rd Ed., Wiley and Sons, Vol I (1975).

[17] G. Socrates, in Infrared Characteristic Groups Frequencies. Tables and Charts, John Wiley \& Sons, Chichester, UK, 1994.

[18] A. Arenillas, F. Rubiera, C. Pevida, J.J. Pis, J. Anal. Appl. Pyrol. 65 (2002) 57.

[19] J.E. Varey, C.J. Hindmarsh, K.M. Thomas, Fuel 75 (1996) 164.

[20] R.M. Carangelo, P.R. Solomon, D.J. Gerson, Fuel 66 (1987) 960.

[21] D. Shao, W.P. Pan, C.L. Chou, Prep ACS, Div. Fuel Chem. 37 (1992) 108.

[22] I. Pitkanen, J. Huttunen, H. Halttunen, R. Vesterinen, J. Thermal Anal. Calor. 56 (1999) 1253.

[23] K. Ismail. O. Sirkecioglu, J.M. Andresen, S.D. Brown, P.J. Hall, C.E. Snape, Polymer 37 (1996) 4041.

[24] D. Bodzek, A. Marzec, Fuel 60 (1981) 47.

[25] W.R. Ladner, Fuel Process. Technol. 20 (1988) 207. 
[26] F. Derbyshire, A. Marzec, H.R. Schulten, M.A. Wilson, A. Davis, P. Tekely, J.J. Delpuech, A. Jurkiewicz, C.E. Bronnimann, R.A. Wind, G.E. Maciel, R. Narayan, K. Bartle, C. Snape, Fuel 68 (1989) 1091.

[27] M.W. Haenel, Fuel 71 (1992) 1211.

[28] M.L. Gorbaty, Fuel 73 (1994) 1819.

[29] K.H. van Heek, Fuel 79 (2000) 1.

[30] W. Hodek, J. Kirschstein, K.H. van Heek, Fuel 70 (1991) 424.

[31] R. Cypres, B. Bettens, Tetrahedron 30 (1974) 1243.

[32] C.B. Danheux, C. Delaunois, N.C. Quyen, Fuel Process. Technol. 1 (1977) 57.

[33] M. Blazsó, J. Anal. Appl. Pyrolysis 25 (1993) 25.

[34] R. García, A. Arenillas, J.L. Crespo, J.J. Pis, S.R. Moinelo, Energy \& Fuels 16 (2002) 935.

[35] R.A. Friedel, in Applied Infrared Spectroscopy, Ed. D.N. Kandall, Reinhold Publishing Corporation, New York, USA, 1966, Cap. 10, p. 312.

[36] P.C. Painter, R.W. Snyder, M. Starsinic, M.M. Coleman, D.W. Kuahn, A. Davis, Applied Spectroscopy 35 (1981) 475 . 
Table 1. Proximate and ultimate analyses of the samples studied

\begin{tabular}{|c|c|c|c|c|c|c|c|c|}
\hline \multirow{2}{*}{ Sample } & \multicolumn{3}{|c|}{ Proximate analysis $(\% \mathrm{wt})$} & \multicolumn{5}{|c|}{ Ultimate analysis (\% wt, daf) } \\
\hline & Moisture & $\operatorname{Ash}(\mathrm{db})$ & $\mathrm{VM}(\mathrm{db})$ & $\mathrm{C}$ & $\mathrm{H}$ & $\mathrm{N}$ & S & $\mathrm{O}$ \\
\hline PVP & 10.4 & 0.0 & 97.0 & 64.1 & 7.9 & 12.7 & 0.0 & 15.3 \\
\hline $\mathrm{p} 4 \mathrm{VP}$ & 48.7 & 0.0 & 95.7 & 84.8 & 6.0 & 9.2 & 0.0 & 0.0 \\
\hline PTC & 0.3 & 0.0 & 91.4 & 73.9 & 2.1 & 0.0 & 0.0 & 24.0 \\
\hline PFR & 2.7 & 0.0 & 52.7 & 71.3 & 5.7 & 0.0 & 0.0 & 23.0 \\
\hline Mixture & 5.8 & 0.0 & 67.1 & 70.0 & 5.7 & 4.1 & 0.0 & 20.2 \\
\hline $\mathrm{SC}$ & 2.9 & 0.0 & 39.2 & 81.8 & 5.4 & 2.6 & 0.0 & 10.2 \\
\hline $\mathrm{CA}$ & 1.4 & 7.6 & 37.7 & 84.4 & 5.5 & 1.8 & 1.6 & 6.7 \\
\hline
\end{tabular}

db: dry basis

daf: dry ash free 


\section{List of figures:}

Figure 1. Model compounds used for the preparation of the synthetic coal.

Figure 2. FT-IR spectra of the individual model compounds.

Figure 3. Deconvolution of the rate of mass loss curve obtained during the pyrolysis of the individual model compounds.

Figure 4. Gaseous compounds evolution followed by MS during the pyrolysis of the individual model compounds.

Figure 5. Gaseous compounds evolution followed by FTIR during the pyrolysis of the individual model compounds.

Figure 6. Deconvolution of the rate of mass loss curve obtained during the pyrolysis of the physical mixture of the model compounds.

Figure 7. FT-IR spectra of the physical mixture of model compounds, the synthetic coal (SC) and the bituminous coal (CA).

Figure 8. Mass loss profiles during the pyrolysis of the synthetic coal (SC) and the bituminous coal (CA).

Figure 9. Deconvolution of the rate of mass loss curve obtained during the pyrolysis of the synthetic coal.

Figure 10. Gaseous compounds evolution followed by MS during the pyrolysis of the synthetic coal ( $\mathrm{SC}-$ ) and the bituminous coal ( $\mathrm{CA} \square)$.

Figure 11. Gaseous compounds evolution followed by FTIR during the pyrolysis of the synthetic coal $(\mathrm{SC}-)$ and the bituminous coal $(\mathrm{CA} \square)$. 


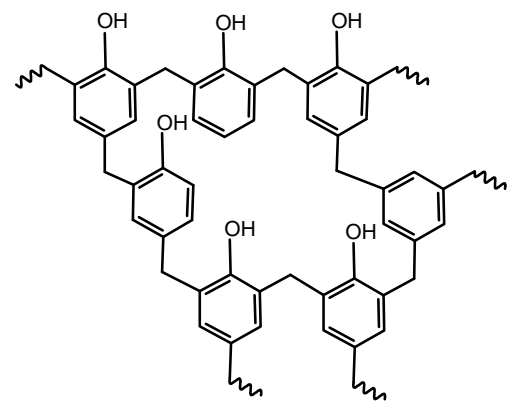

PFR

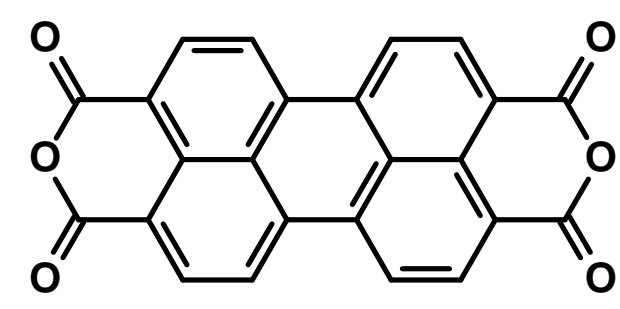

PTC
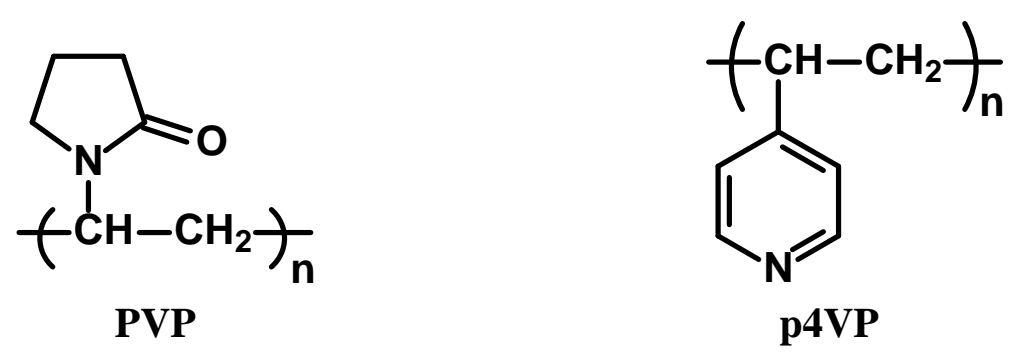

Figure 1 

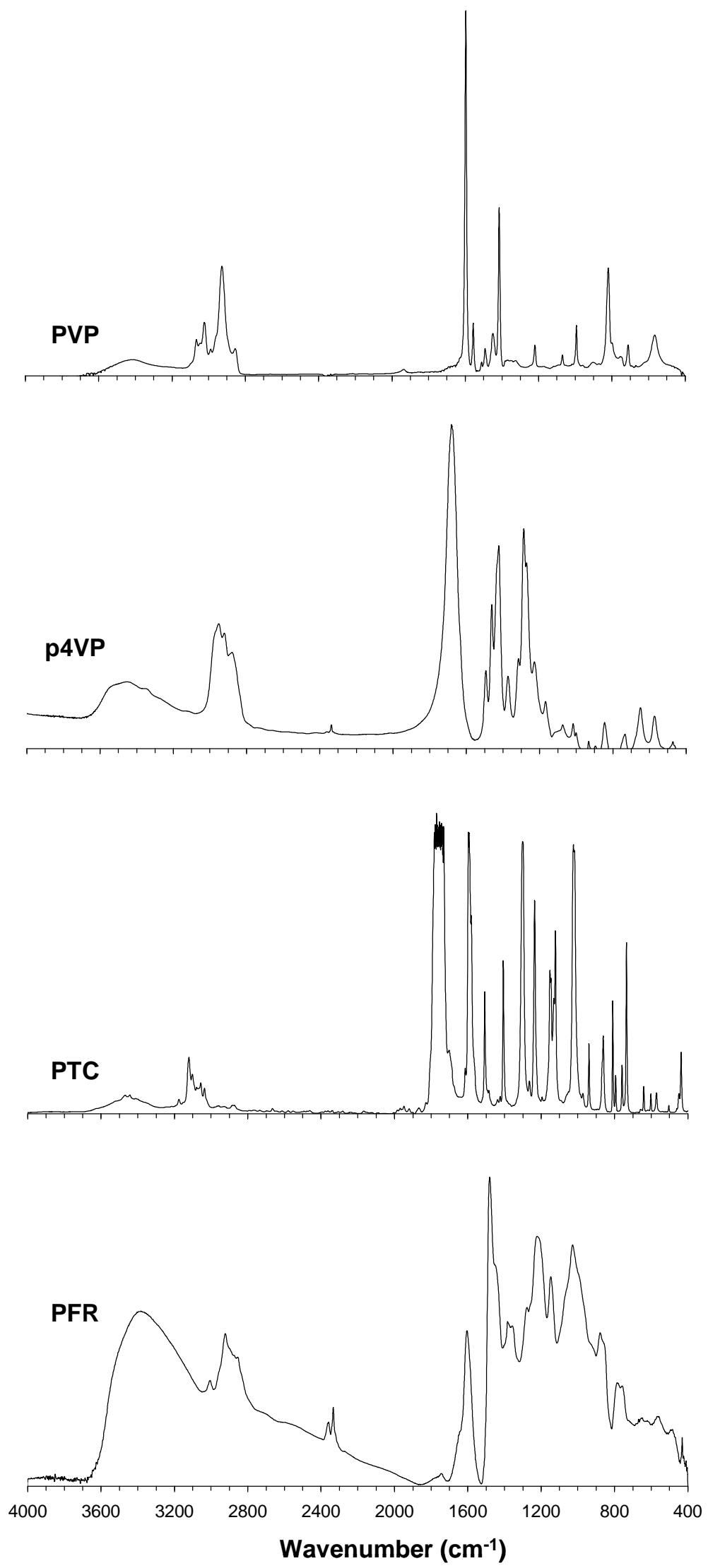

Figure 2 

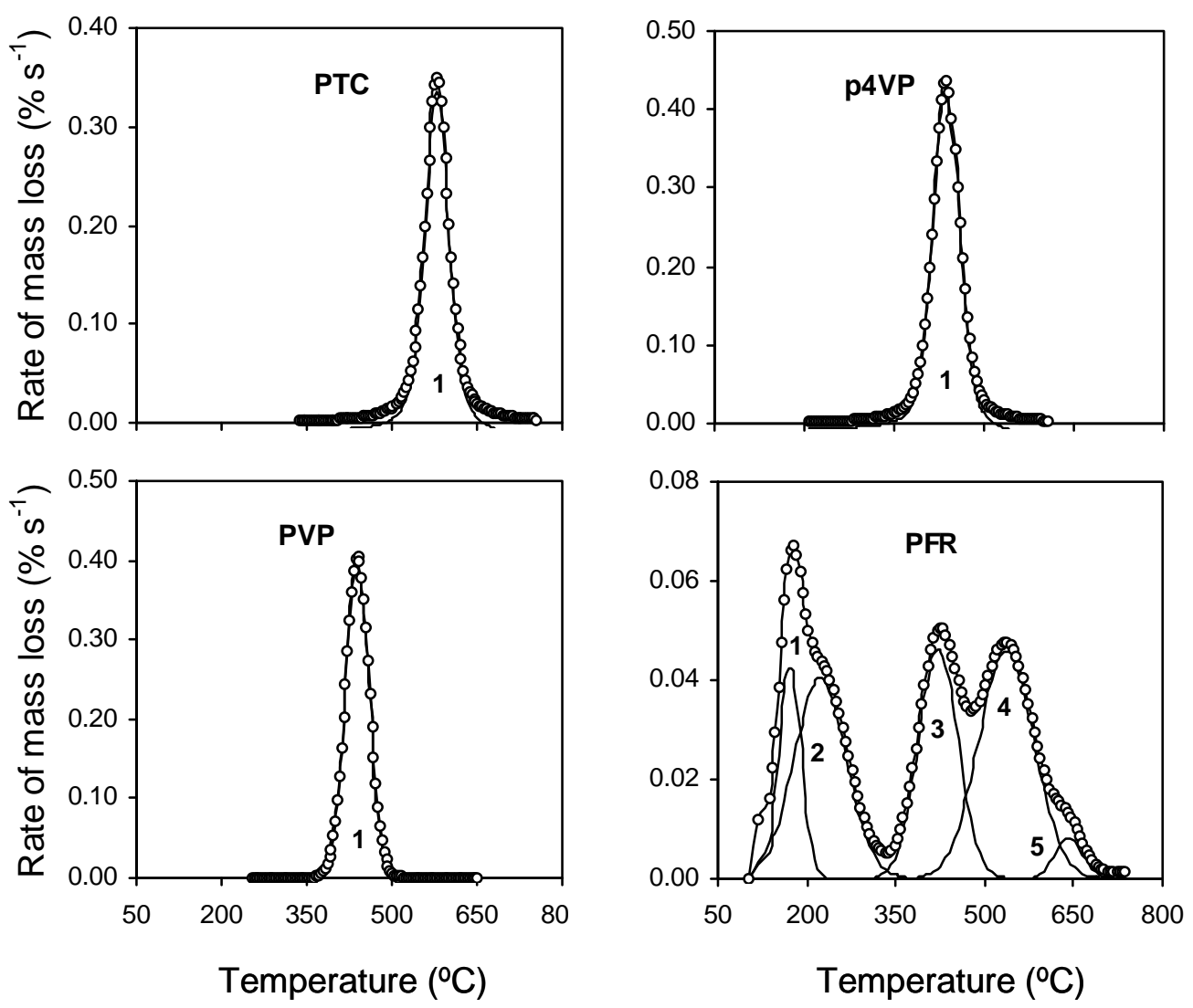

Figure 3 


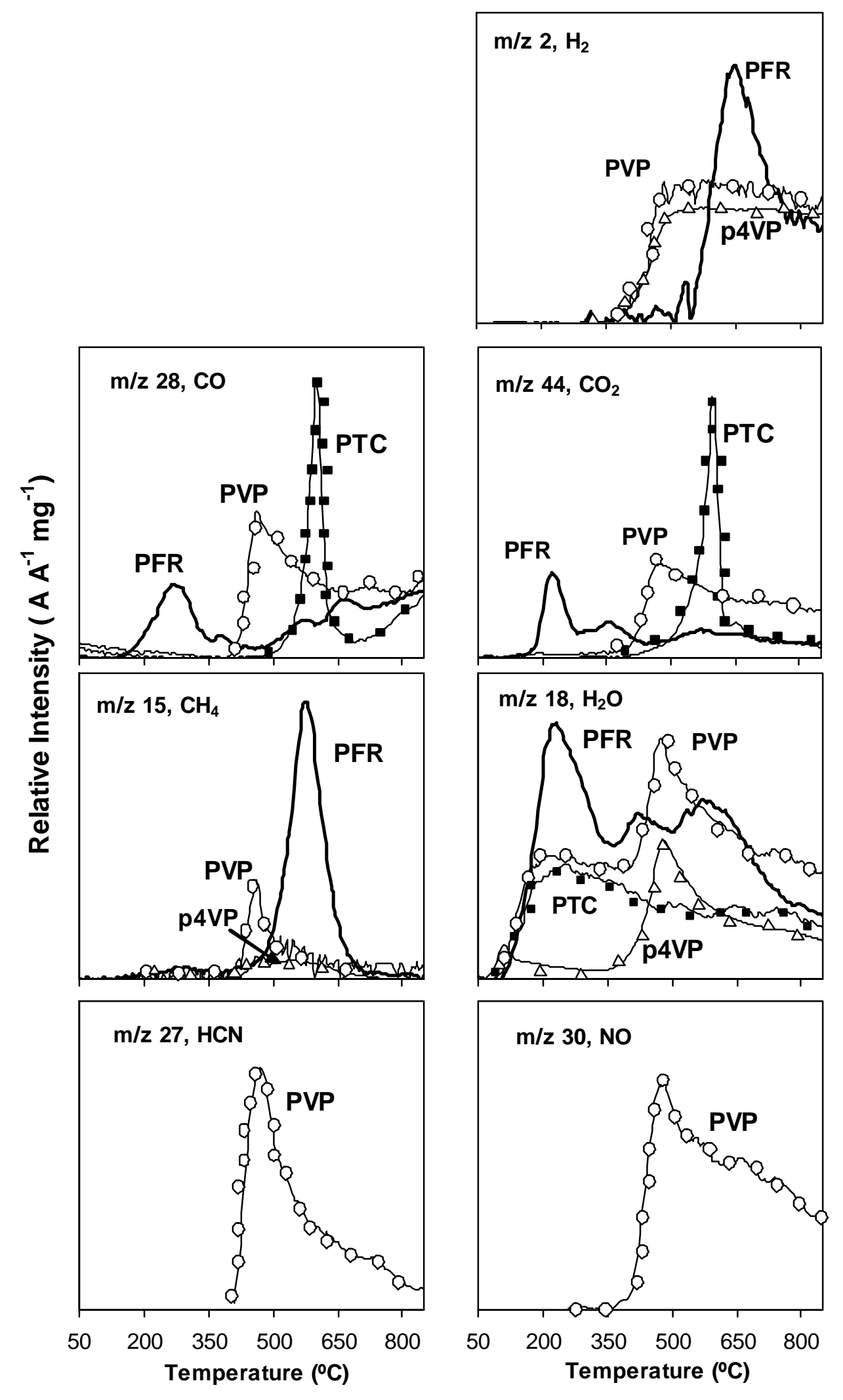

Figure 4 

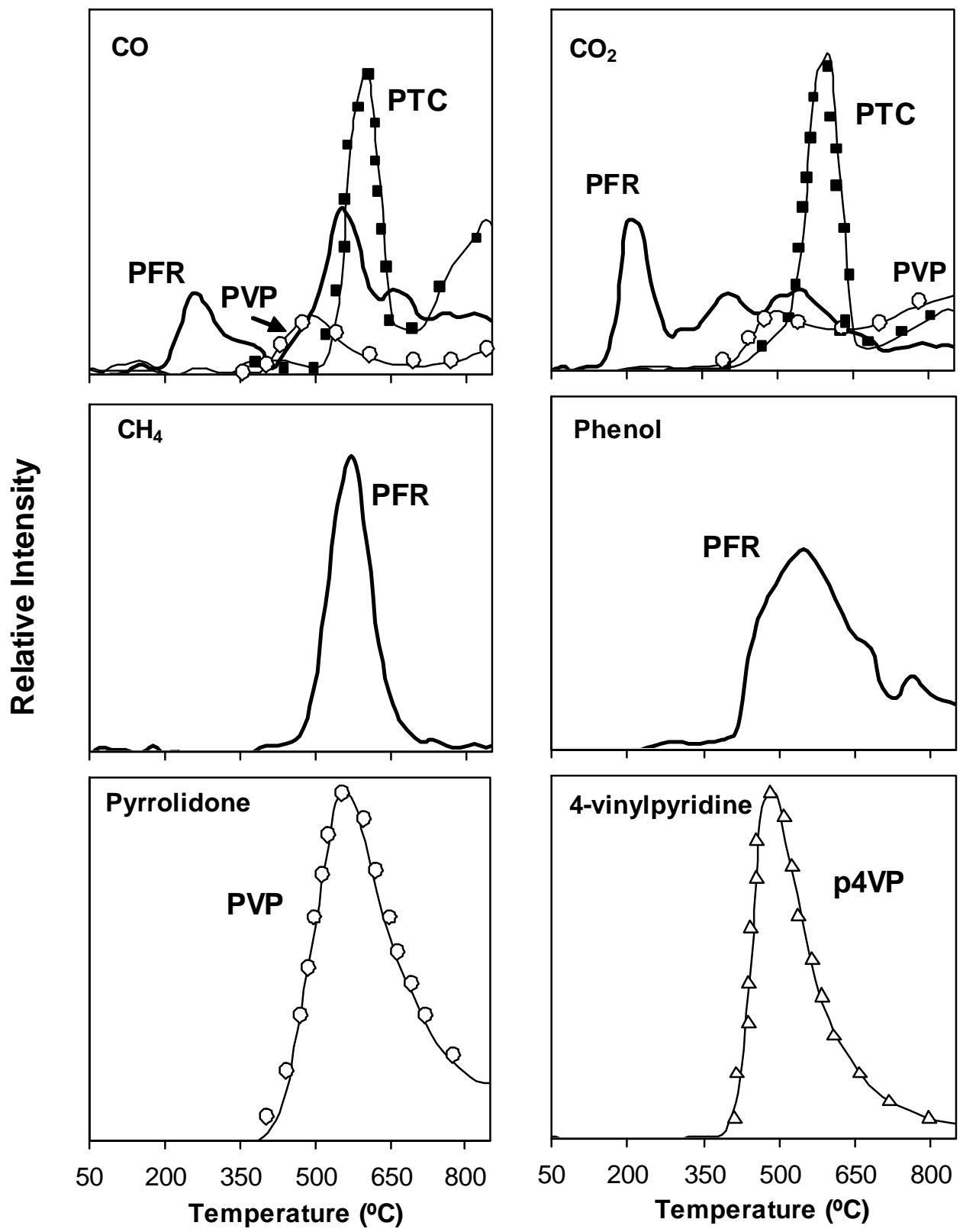

Phenol
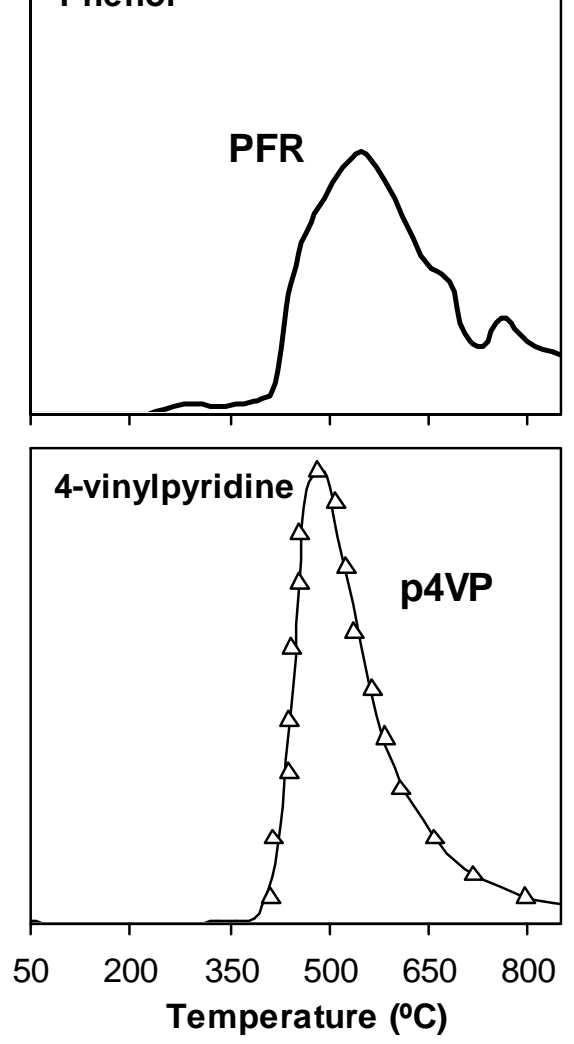

Figure 5 


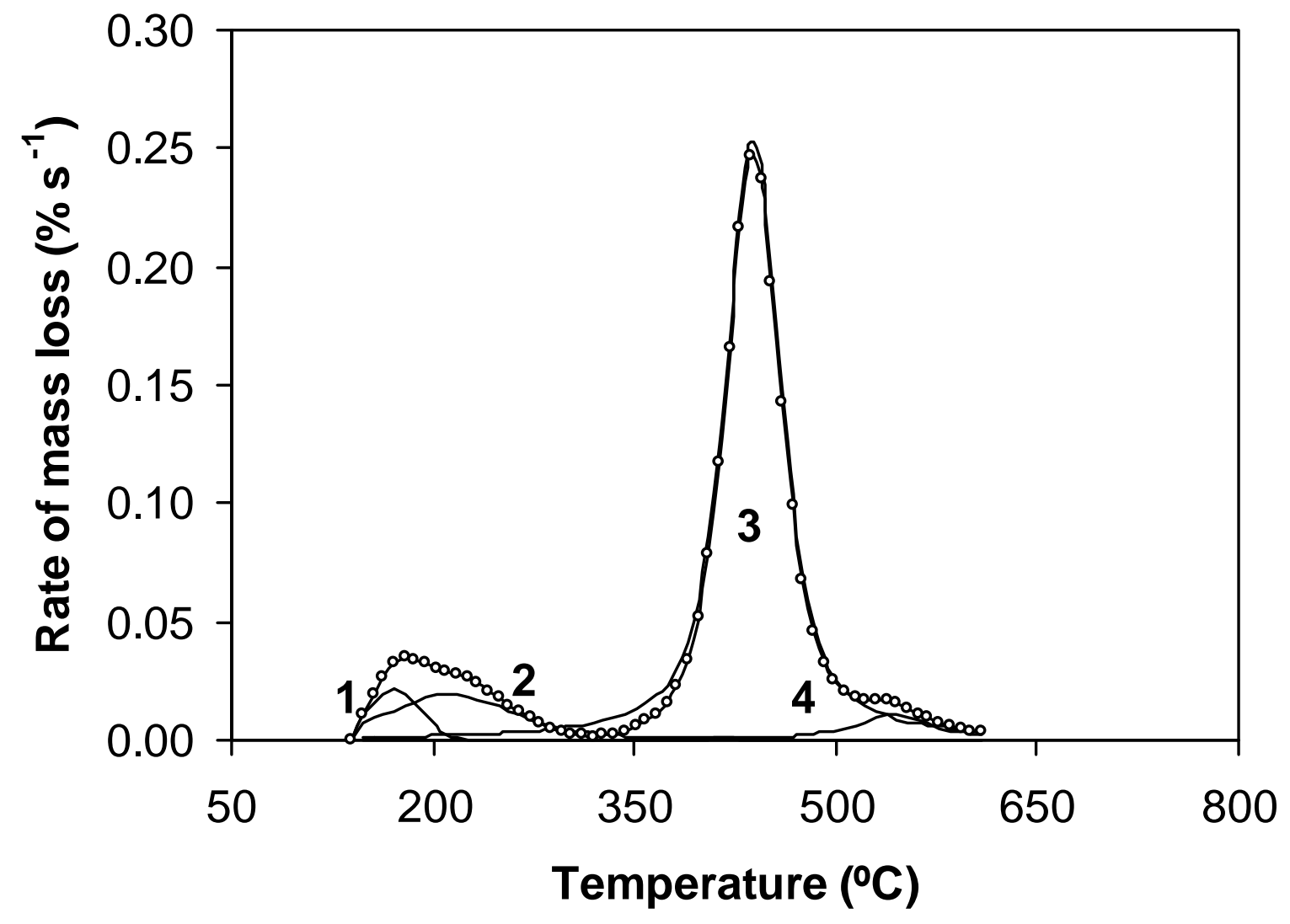

Figure 6 

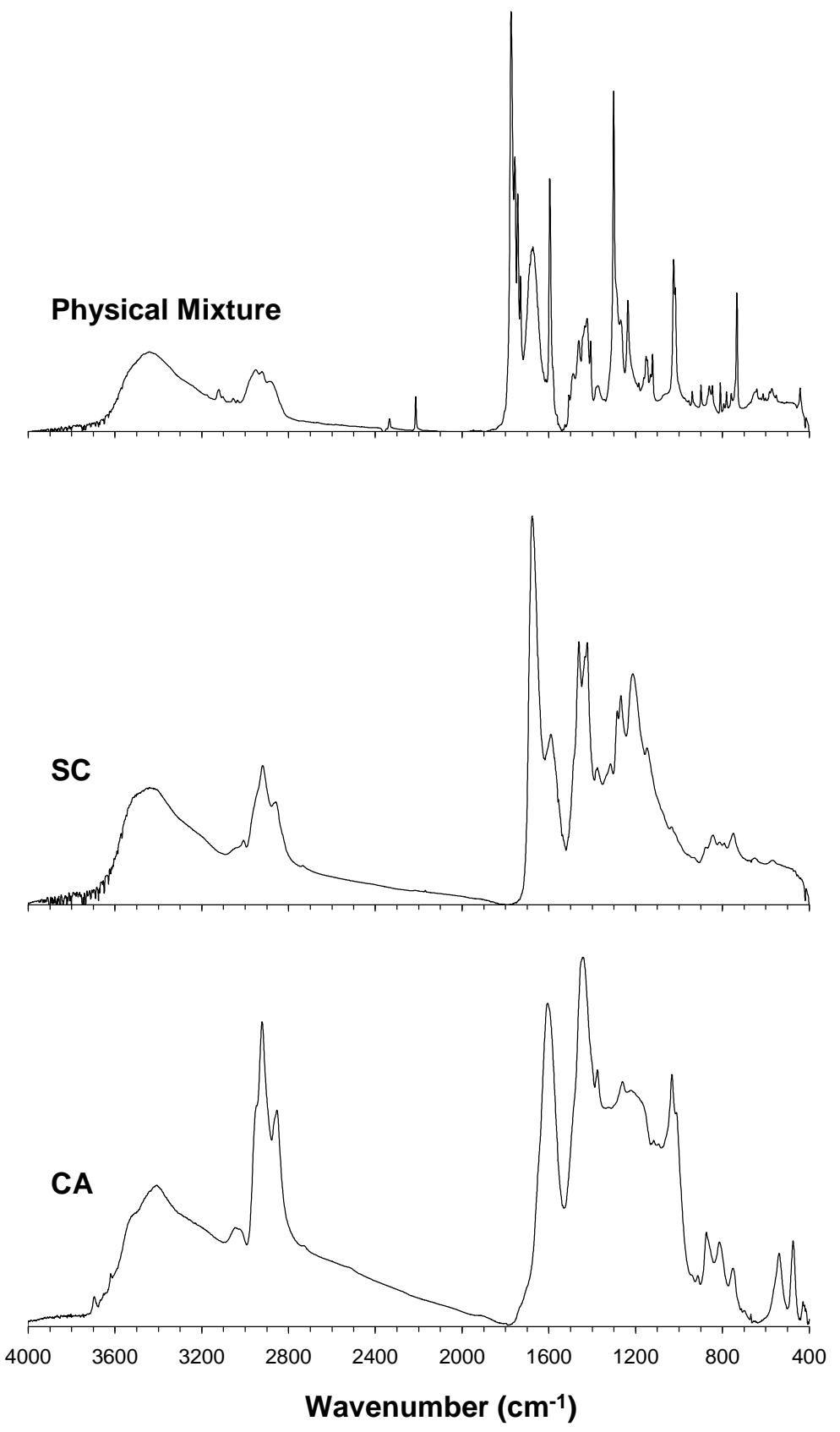

Figure 7 


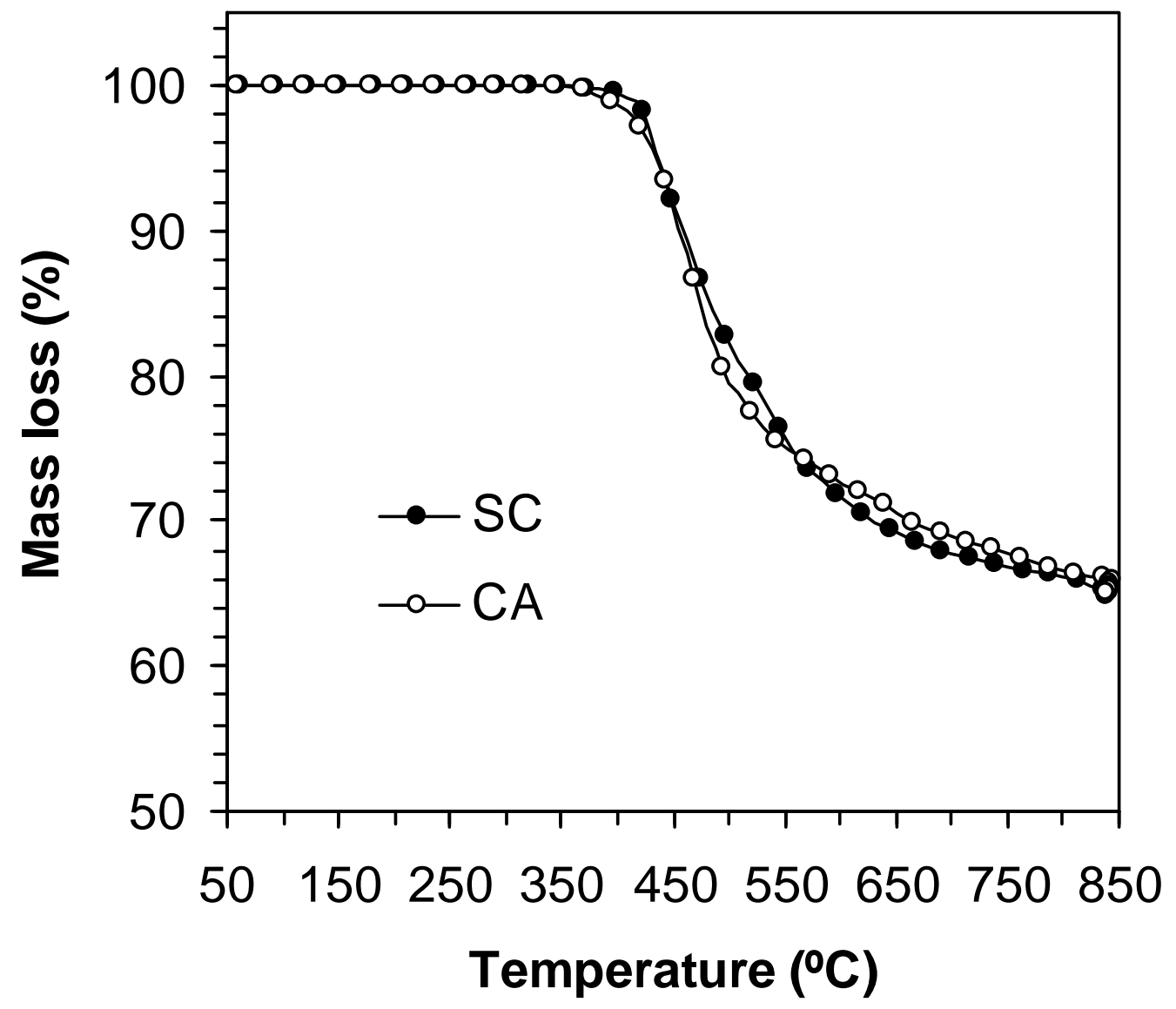

Figure 8 


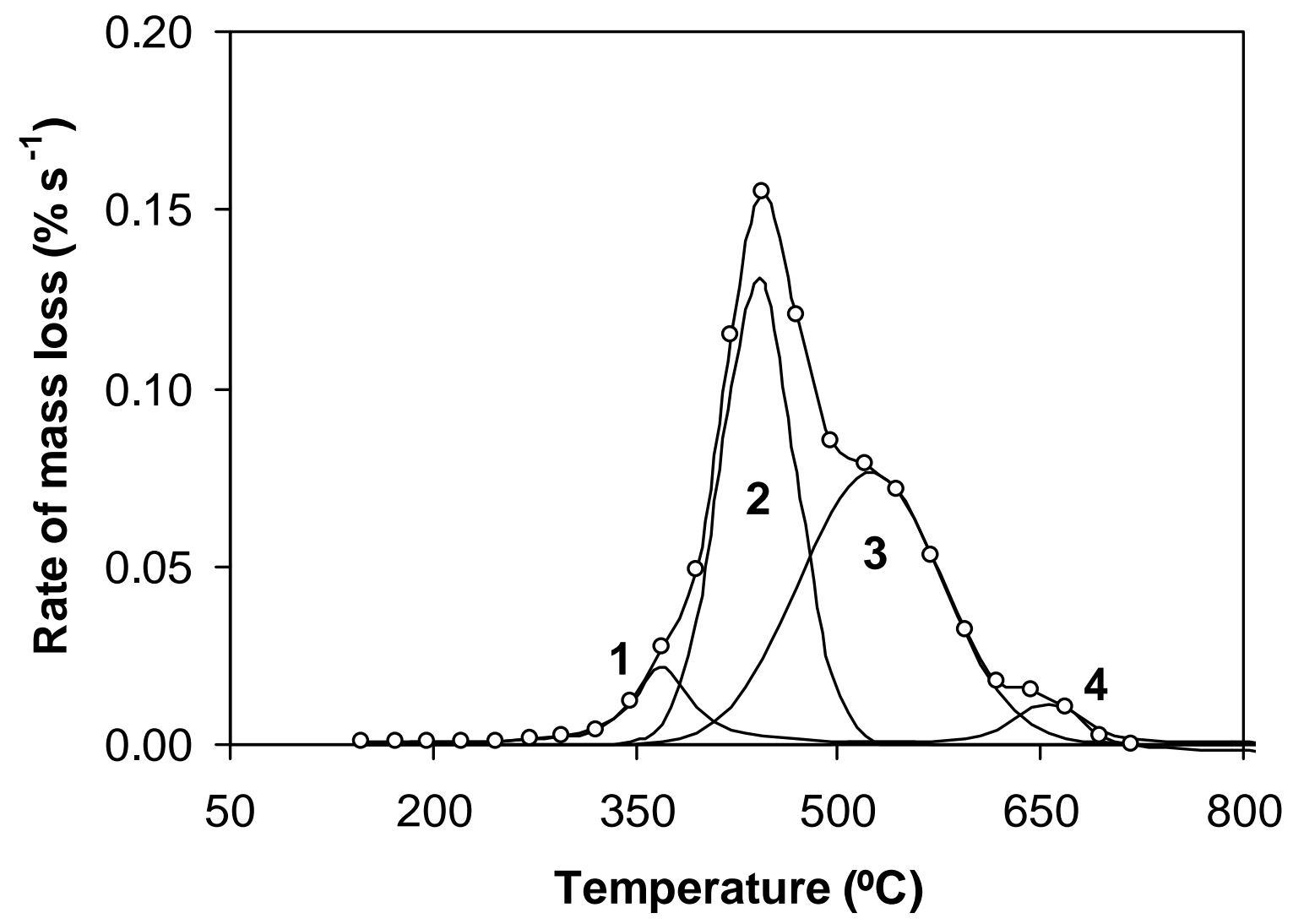

Figure 9 


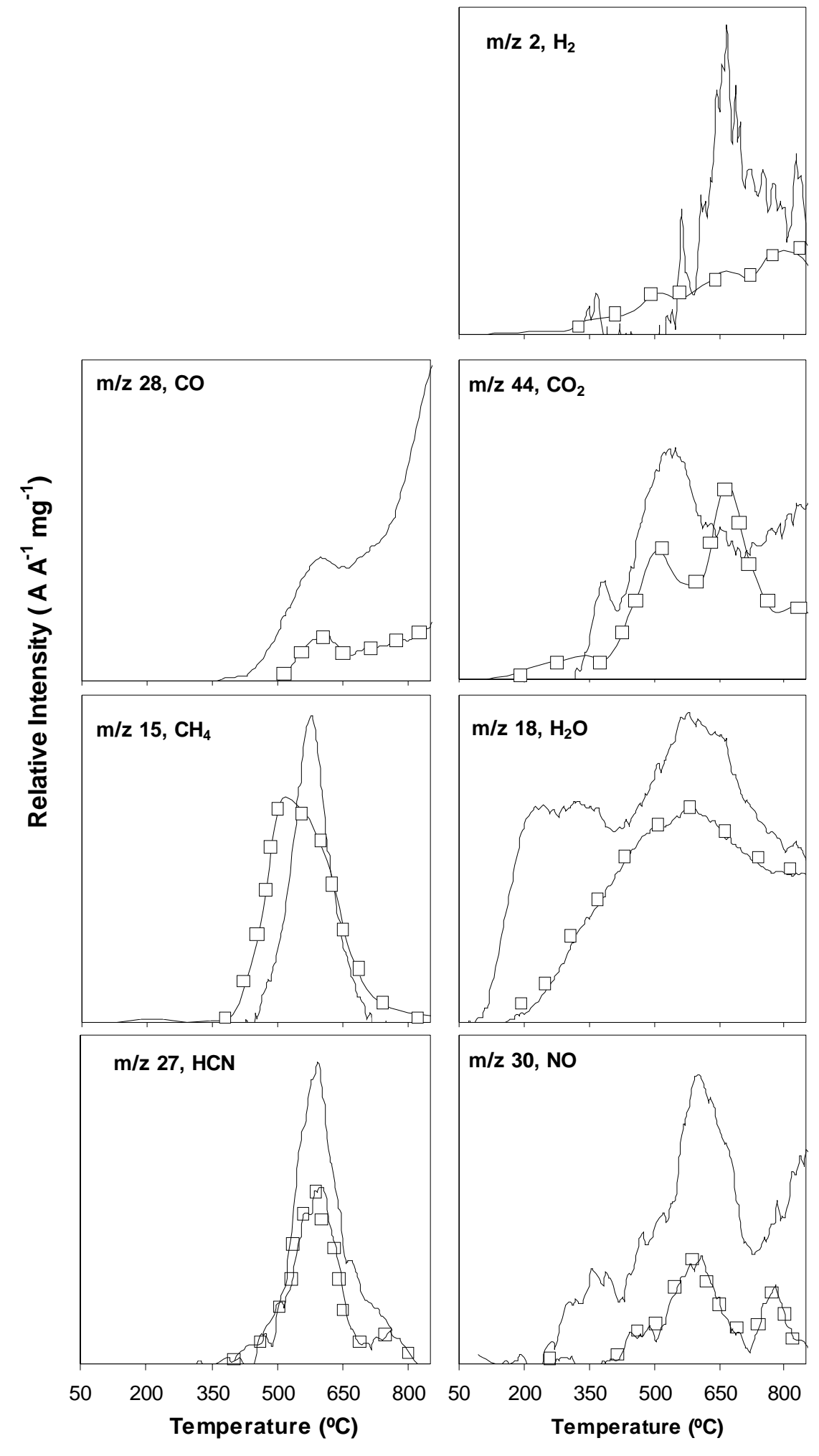

Figure 10 

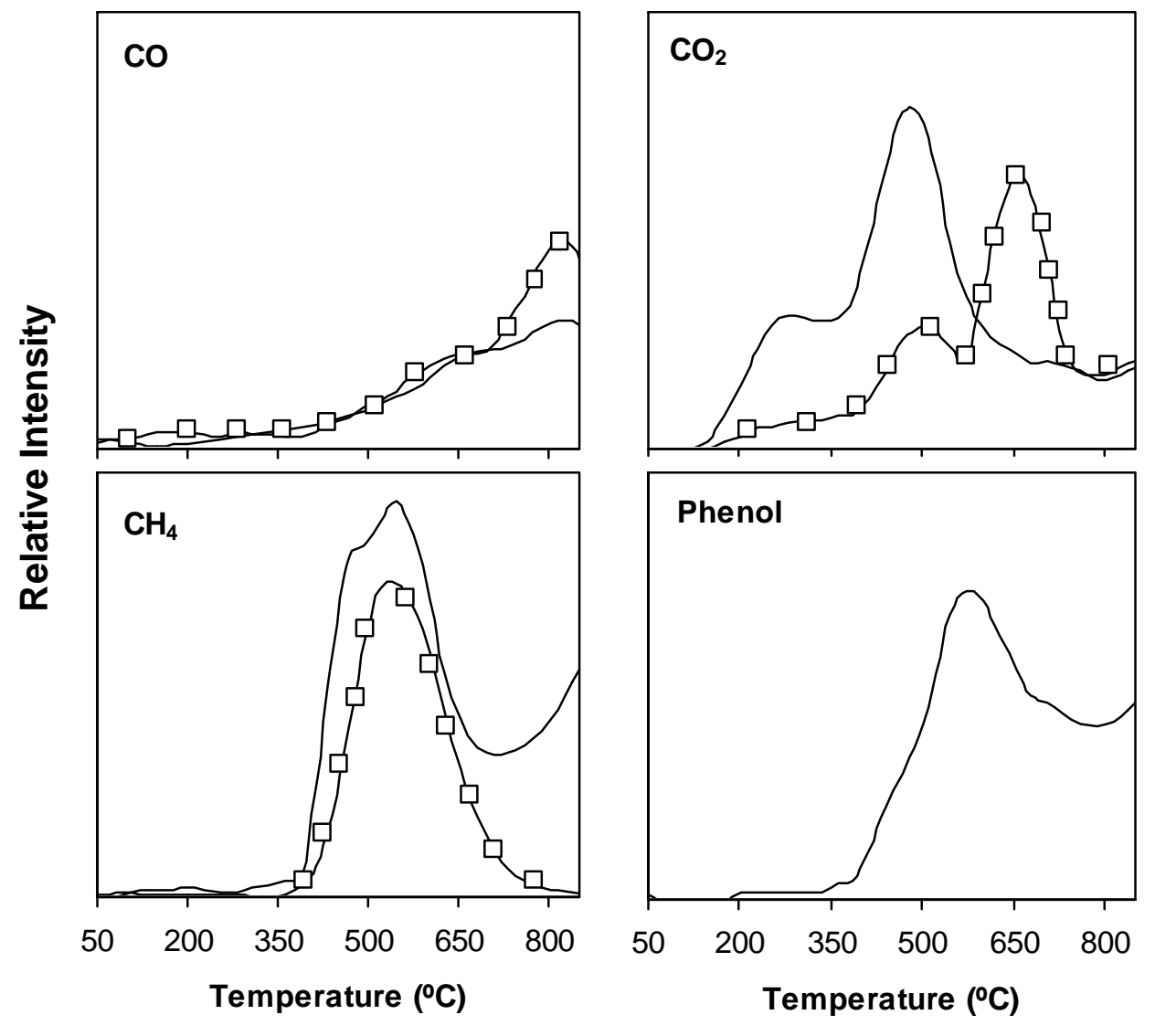

Figure 11 